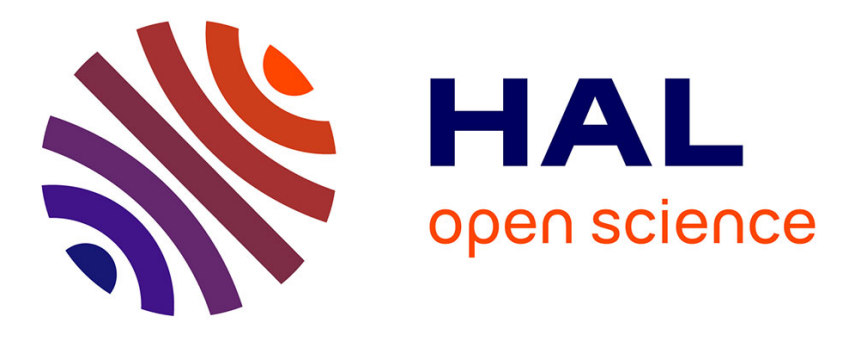

\title{
The role of abnormal grain growth on solid-state dewetting kinetics
}

Galit Atiya, Dominique Chatain, Vissarion Mikhelashvili, Gadi Eisenstein, Wayne D Kaplan

\section{- To cite this version:}

Galit Atiya, Dominique Chatain, Vissarion Mikhelashvili, Gadi Eisenstein, Wayne D Kaplan. The role of abnormal grain growth on solid-state dewetting kinetics. Acta Materialia, 2014, 81, pp.304 314. 10.1016/j.actamat.2014.08.038 . hal-01722656

\section{HAL Id: hal-01722656 https://hal-amu.archives-ouvertes.fr/hal-01722656}

Submitted on 16 Apr 2018

HAL is a multi-disciplinary open access archive for the deposit and dissemination of scientific research documents, whether they are published or not. The documents may come from teaching and research institutions in France or abroad, or from public or private research centers.
L'archive ouverte pluridisciplinaire HAL, est destinée au dépôt et à la diffusion de documents scientifiques de niveau recherche, publiés ou non, émanant des établissements d'enseignement et de recherche français ou étrangers, des laboratoires publics ou privés. 


\title{
The Role of Abnormal Grain Growth on Solid-State Dewetting Kinetics
}

\author{
Galit Atiya $^{\mathrm{a}}$, Dominique Chatain ${ }^{\mathrm{b}}$, Vissarion Mikhelashvili ${ }^{\mathrm{c}}$, Gadi Eisenstein ${ }^{\mathrm{c}}$, and \\ Wayne D. Kaplan ${ }^{\mathrm{a}, 1}$
}

${ }^{\mathrm{a} D e p a r t m e n t ~ o f ~ M a t e r i a l s ~ S c i e n c e ~ a n d ~ E n g i n e e r i n g, ~ T e c h n i o n-I s r a e l ~ I n s t i t u t e ~ o f ~ T e c h n o l o g y, ~}$ Haifa 32000, Israel, ' Aix Marseille Université, CNRS, CINaM UMR 7325, Marseille, France, ${ }^{c}$ Department of Electrical Engineering, Technion-Israel Institute of Technology, Haifa 32000, Israel

\begin{abstract}

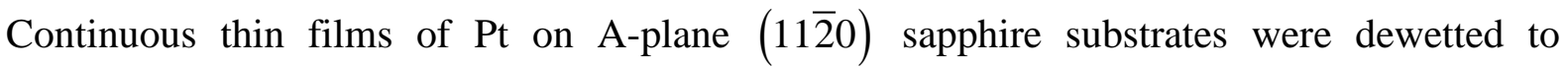
characterize the morphological evolution and dewetting kinetics at $800^{\circ} \mathrm{C}$ using an oxygen partial pressure of $10^{-20}$ atm. Hole growth kinetics were studied focusing on partially dewetted samples. Four different low-index orientation relationships were found between the Pt and sapphire substrate by electron backscattered diffraction combined with transmission electron diffraction patterns. Abnormal grains adjacent to the holes with a small deviation from one of the low-index orientation relationships were observed. It was also found that the difference in the heights of the abnormal grains adjacent to the holes (rim-height) is influenced by the initial position of the hole, and the existence of grains with low-energy interface orientation, and not only by diffusivity rates dictated by surface orientation as described in existing edge-retraction models. The existence of low-index orientation relationships are seen as the driving force for abnormal grain growth in the vicinity of the holes, and is a dominant factor in controlling the dewetting rate of thin metal films on oxide surfaces.
\end{abstract}

Keywords: Interfaces; Abnormal grain growth, Crystallographic orientation; EBSD; Solidstate dewetting

Corresponding Author: kaplan@tx.technion.ac.il 


\section{Introduction}

The mechanism(s) and kinetics of dewetting of thin films have been extensively investigated over the last few decades, in an attempt to understand the dominant mechanism which controls the dewetting process. It is well known that thin films are not stable and tend to break-up into isolated particles (or droplets in the liquid state), where the dewetting process is driven by minimization of the total surface/interface/grain boundary energy. Dewetting is commonly used for micro-electronic applications to form nanometer length-scale crystals for silicon on insulator structures (SOI) [1,2], catalysts for growth of carbon nanofibers and nanotubes [3], and electrical memory and optical devices [4,5].

Without a detailed understanding of the mechanisms and kinetics of the dewetting process, its technological application to form specific structures and arrays will be limited. Different parameters affect the dewetting kinetics and the final particle morphology, such as the initial film thickness, the film deposition method, alloying elements, the temperature used for dewetting, and the partial pressure of gas species (in particular oxygen) [6-11]. While solidstate dewetting depends on many parameters, it can be divided into three main stages: hole nucleation and grain growth (for polycrystalline thin films), hole growth and "finger" formation, and film break-up. The first stage (hole nucleation) was originally modeled by Mullins who showed that for polycrystalline films grain boundaries and grain boundary triple junctions play an important role in the nucleation of holes [12,13]. Assuming that grain boundary grooving is the initial mechanism for hole nucleation, Srolovitz and Safran used the ratio of surface to grain boundary energy to establish criteria for hole nucleation [14]. Based on initial results indicating that void nucleation at metal-oxide interfaces may lead to the nucleation of holes [15], Shaffir et al. conducted controlled solid-state dewetting experiments of gold on zirconia, which showed that hole nucleation can initiate at relatively high energy metal-oxide interfaces via nucleation of voids [16]. Hole nucleation (via grain boundary grooves or void growth from the interface) may occur concurrently with grain growth of the initially continuous polycrystalline thin film. Grain growth is driven by reduction of the total grain boundary area to minimize grain boundary energy [17]:

$$
\frac{\mathrm{d} \overline{\mathrm{r}}}{\mathrm{dt}}=\overline{\mathrm{m}} \overline{\mathrm{g}}_{\mathrm{gb}} \overline{\mathrm{k}}
$$

where $\bar{r}$ is the average grain radius, $\bar{\gamma}_{g b}$ is the average grain boundary energy, $\overline{\mathrm{m}}$ is the average grain boundary mobility, and $\overline{\mathrm{k}}$ is the average boundary curvature. The influence of grain growth on hole nucleation has been the focus of several theoretical studies, indicating that at a stagnated grain size (radius) of $R_{\text {Stagnation }} \approx \gamma_{f}^{h} / \gamma_{g b} \approx 2.5 h$, where $h$ is the film thickness, the driving force for further growth of normal grains decreases significantly and the preferential growth of grains with specific crystallographic orientations will be favored $[18,19]$.

Abnormal grain growth (AGG) in thin films was simulated by Frost et al. to estimate the driving force for AGG without the influence of holes [20]. Simulations showed that only minor changes in the free surface energy between adjacent grains is required to drive AGG. Abnormal grains were seen by Müller and Spolenak at the edge of holes during dewetting of Au films on $\mathrm{SiN}_{\mathrm{X}} / \mathrm{SiO}_{2} / \mathrm{Si}[21]$.

The second step in dewetting is hole growth, which forms via film edge retraction. The first model for the edge retraction phenomena was based on experimental observations and was 
proposed by Brandon and Bradshaw [22]. In their model, assuming single crystal films and isotropic surface energies, surface diffusion resulted in mass accumulation and the formation of a rim at the edge of the hole. When the rim becomes larger the hole growth rate decreases due to decreasing radius of curvature. Jiran and Thompson modified the Brandon and Bradshaw model, explaining that build-up of the rim around the hole results in the Rayleigh instability of a cylinder, which allows for surface diffusion in all directions and break-up into fingers and then islands, thus facilitating the dewetting process [23]. The evolution of the shape and position of the retracting rim was also addressed via different models [24-26]. Srolovitz and Safran assumed isotropic surface energies and noted that the depth of the valley which forms after the rim increases as the edge retracts, until it contacts the substrate which leads to pinch-off [24]. Klinger et al. described the retraction kinetics of single crystal films of a fully faceted edge with highly anisotropic surface energies, where they concluded that the formation of hills with the absence of a depression indicated "strong anisotropy" of the edge and results in slow-down of dewetting [25]. More recently, Zucker et al. demonstrated that the retraction distance of a faceted edge as a function of time corresponds to $x_{0} \propto t^{n}$ (where $n=0.436$ ), and that the rim height and width depend on $n=0.254$ and $n=0.193$, respectively [26]. The two first kinetic models described above assumed isotropic surface energies and the absence of grain boundaries, which is clearly not the case for polycrystalline films. While Zucker et al. took anisotropic surface energies into account, the influence of grain growth on the kinetics of dewetting was not considered, although it may have a significant effect on the dewetting mechanisms which control the dewetting rate.

Dewetting experiments are also often used to extract kinetic parameters such as the surface diffusion coefficient $[27,28]$. This form of analysis was first used by Jiran and Thompson via the correlation of film coverage as a function of time [29]:

$$
X_{\text {dewet }}=1-\exp \left[-N_{h} \pi v_{h}^{2}\left(t-t_{i}\right)^{2}\right]
$$

where $X_{\text {dewet }}$ is hole coverage area, $N_{h}$ the number of holes, $t_{i}$ is the incubation time, $v_{h}=\frac{2 D_{s} v_{s} \Omega^{2} \gamma_{f v}}{k T h^{3}}$ where $D_{s}$ is the coefficient for surface diffusion, $\Omega$ is the atomic volume, $v_{s}$ is the number of surface atoms, $\gamma_{f v}$ is the surface energy, $\mathrm{k}$ is Boltzmann's constant, $\mathrm{T}$ is temperature and $\mathrm{h}$ is the film thickness.

However, the dewetting kinetics may be influenced by additional microstructural parameters, such as surface/interface perturbations, interface energy, grain boundary energy, etc. As will be demonstrated here, hole formation and growth in thin films is often heterogeneous, and the coverage as a function of time varies with the position of the hole across the substrate. In addition, the approach summarized in equation (2) assumes a constant rate of growth of dewetted areas and a constant number of hole nuclei, and ignores microstructural aspects of the dewetting process, including hillock formation, interface void nucleation, and the influence of triple lines intersecting the substrate on hole nucleation and growth. The current study focuses on the phenomenon of AGG adjacent to holes during solid-state dewetting, and how AGG may influence the kinetics of dewetting. In addition, the influence of low-index orientation relationships (OR) between the film material and substrate on the hole growth rate and AGG is addressed.

\section{Experimental Methods}




\subsection{Sample Preparation}

Sapphire substrates (99.99\% purity) with $(11 \overline{2} 0)$ parallel to the substrate surface (A-plane orientation) were provided by Gavish Industrial Technologies \& Materials (Omer, Israel). Polished substrates were ultrasonically cleaned in acetone and ethanol, and thermally annealed for 2 hours at $1100^{\circ} \mathrm{C}$ in $\mathrm{Ar}+2 \% \mathrm{O}_{2} .50 \mathrm{~nm}$ thick Pt films were deposited by electron beam evaporation at ambient temperature, at a deposition rate of $\sim 0.1-0.2 \AA /$ sec under high vacuum conditions ( $2 \times 10^{-7}$ Torr). Annealing at $800^{\circ} \mathrm{C}$ for different periods of time was conducted to (partially) dewet the films, using a heating and cooling rate of $10^{\circ} \mathrm{C} / \mathrm{min}$. The shortest annealing time ( 1 minute) was conducted to examine the influence of heating and cooling rates. Dewetting was conducted in a sapphire tube furnace under flowing $\mathrm{Ar}+\mathrm{H}_{2}$ (99.999\%) at a partial pressure of oxygen $\mathrm{P}\left(\mathrm{O}_{2}\right)<10^{-20}$ atm.

\subsection{Characterization Methods}

The bare $\left(\alpha-\mathrm{Al}_{2} \mathrm{O}_{3}\right)$ surface morphology after annealing in $\mathrm{Ar}+\mathrm{O}_{2}$ at $1100^{\circ} \mathrm{C}$ for 2 hours was characterized using atomic force microscopy (AFM; Omnicron-UHV-SPM). The asdeposited microstructure was characterized by X-ray diffraction (XRD; Rikagu Smart Lab XRay Diffractometer at $\lambda=0.1540598 \mathrm{~nm}$ ) and the film thickness was confirmed by crosssection microscopy on samples prepared using a dual-beam focused ion beam system (FIB; FEI Strata 400s).

The dewetted film morphology was characterized by high resolution scanning electron microscopy (HRSEM; Zeiss Ultra-Plus FEG-SEM) after coating the samples with a thin carbon layer to avoid charging under the electron beam. SEM (FEI E-SEM Quanta 200) equipped with electron backscattered diffraction (EBSD) was used to determine the misorientation between Pt grains, and the OR between Pt grains and the sapphire substrate (using HKL software).

The grain size distribution and film coverage as a function of dewetting time was analyzed from HRSEM micrographs. To determine the grain size, a Matlab program was used for $~ 300$ grains for each sample [30]. The coverage was analyzed using Image $J$ [31]. The volume of Pt diffused from the hole to the hole-rims was determined from contact-mode AFM data [32].

High resolution transmission electron microscopy (HRTEM) was conducted using a monochromated and (image) aberration corrected TEM (FEI Titan 80-300 kV S/TEM). Site specific TEM sample preparation was conducted using the in-situ lift-out technique [33,34].

\section{$3 \quad$ Results}

The sapphire morphology after annealing at $1100^{\circ} \mathrm{C}$ for 2 hours, before Pt deposition, was characterized using contact-mode AFM as shown in Figure 1. Terraces formed on the substrate, with a terrace width of $\sim 400 \mathrm{~nm}$ and step heights of $\sim 0.3 \mathrm{~nm}$.

The as-deposited 50nm thick Pt film was characterized by XRD, and a $\{111\}$ preferred orientation of the Pt on the substrates was found. In addition, $\{200\}$ and $\{220\}$ reflections were also present, but at low intensities (Figure 2). Cross-section TEM of the as-deposited films confirmed that the initial Pt film was continuous and had a thickness of 50nm (Figure 3 ). The grains of the as-deposited film are columnar in morphology, with a width of $\sim 20$ $30 \mathrm{~nm}$. 
The morphology of the film after annealing at $800^{\circ} \mathrm{C}$ as a function of time was characterized using HRSEM, and representative micrographs are presented in Figure 4. The morphological evolution corresponds to the three known stages of the solid-state dewetting process. The first stage, hole nucleation (arrowed pin-holes) and grain growth, is shown in Figure 4a, where the roughness of the Pt film suggests hillock formation [35]. This most likely occurs during heating to elevated temperatures to release compressive stresses in the film, resulting from differences in the thermal expansion coefficient of Pt $\left(10.84 \times 10^{-6} \mathrm{~K}^{-1}\right)$ [36] and $\mathrm{Al}_{2} \mathrm{O}_{3}$ $\left(8.83 \times 10^{-6} \mathrm{~K}^{-1}\right)$ [37]. The average grain size was measured to be $155 \pm 71 \mathrm{~nm}$, which is significantly larger than the as-deposited grain size of $20-30 \mathrm{~nm}$. The second stage of dewetting, which is hole growth, is presented in Figure $4 \mathrm{~b}$, and confirms formation of faceted rims at the edges of the holes. AGG at the edge of the holes was observed to coincide with hole growth. This phenomenon was also reported by Muller et al. where grains in the vicinity of growing holes were significantly larger compared to grains far from the holes in thin Au films [21]. After one hour anneal the average size of the Pt normal grains was $205 \pm 100 \mathrm{~nm}$ (Figure 5b), which is an increase of $~ 33 \%$ compared to the sample annealed for 1 minute. After 2 hours of annealing the grain size increased to $\sim 240 \pm 95 \mathrm{~nm}$ and the abnormal grains at the edges of the holes were $830 \pm 250 \mathrm{~nm}$, which is $\sim 3$ times larger than the grains far from the holes. Hole growth followed by the classic Rayleigh instability reported by Jiran and Thompson resulted in the formation of polycrystalline "fingers" (Figure 4c) [29]. The third and last stage includes film break-up and the formation of individual particles. Figure 4d shows Pt particles after 48 hours annealing, which are almost at equilibrium.

The normalized hole coverage area as a function of time is plotted in Figure 6. The three stages of dewetting can be assigned to the coverage data, where blue represents the incubation time for the nucleation of holes, red indicates the stage of hole growth and Rayleigh instability, and green represents the formation of individual Pt particles from the polycrystalline fingers. This study focuses on the second stage, characterized by hole growth, which for the present system cannot be described by a continuous model such as that used by Jiran and Thompson because in the present samples the hole growth was found to be heterogeneous [29]. This is a particularly important issue if parameters such as the surface diffusion coefficient are being extracted from dewetting kinetics. Given the appearance of AGG adjacent to the holes, and its possible role in retarding dewetting, further characterization of the abnormal grains was conducted.

A detailed EBSD analysis was conducted on the samples annealed at $800^{\circ} \mathrm{C}$ for 70 minutes and 2 hours. Figure 7a presents a secondary electron micrograph of the area investigated by EBSD after dewetting at $800^{\circ} \mathrm{C}$ for 2 hours. Colored lines are superimposed on the SEM micrograph, indicating the range of misorientation angles between pairs of Pt grains. The abnormal grains are clearly delimited by high angle grain boundaries. Figure $7 \mathrm{~b}$ is an EBSD map which indicates that the Pt film has a preferred $\{111\}$ out of plane orientation. The color code used in Figure $7 \mathrm{~b}$ indicates the deviation distribution from $<111>$ normal to the substrate. While the abnormal grains at the edge of the hole have $<111>$ exactly (within the angular resolution of EBSD) normal to the substrate surface (colored in blue), most of the smaller grains far from the hole have small but significant angular deviations (up to $5^{\circ}$ ) of $<111>$ from the substrate normal.

EBSD was used to analyze potential in-plane preferred orientations. Figure 7c presents the in-plane Pt orientation relative to an arbitrary direction in the plane of the substrate surface. The Pt in-plane orientation based on the color code presented in Figure 7 indicates that while 
there is a $\{111\}$ out-of plane preferred orientation, parallel to the substrate surface the Pt grains have an angular distribution about $<111>$. This over simplified analysis would then indicate a lack of a specific OR between the Pt grains and the sapphire substrate.

To conduct a more detailed analysis of the OR between individual abnormal Pt grains around the circumference of the holes and the sapphire substrate, individual EBSD patterns were fully analyzed, and the following four low-index ORs were found, with angular deviations about the surface normal as presented in Figure 8:
1. $\{\overline{1} \overline{1} 20\}\langle 1 \overline{1} 0 \overline{1}\rangle$ Sapphire $\|\{1 \overline{1} \overline{1}\}\langle 211\rangle_{P t}$
2. $\{\overline{1} \overline{1} 20\}\langle 1 \overline{1} 0 \overline{1}\rangle_{\text {Sapphire } \|}\{1 \overline{1} \overline{1}\}\langle 110\rangle_{P t}$
3. $\{\overline{1} \overline{1} 20\}\langle 1 \overline{1} 0 \overline{2}\rangle_{\text {Sapphire } \|}\{1 \overline{1} \overline{1}\}\langle 211\rangle_{P t}$
4. $\{\overline{1} \overline{1} 20\}\langle 1 \overline{1} 0 \overline{2}\rangle_{\text {Sapphire } \|}\{1 \overline{1} \overline{1}\}\langle 110\rangle_{P t}$

OR 4 is equivalent to the OR which was reported by Curiotto et al. for copper on the same plane of sapphire [38]. Not all the abnormal grains which were investigated had an exact lowindex OR with the substrate. Some grains deviated (up to $6^{\circ}$ ) from one of the low-index ORs listed above as depicted in Figure 8. While a low-index OR implies a low-energy OR, at this stage the Pt films are still partly continuous, have not yet reached equilibrium, and the Pt grains are constrained by neighboring grains. In addition, some of the angular deviation from a low-index OR may be due to strain fields resulting from lattice mismatch with the substrate ( $\sim 4.3 \%)$ and the difference in thermal expansion coefficient between Pt and sapphire, as presented in Figure 7d. Detailed analysis of the normal-sized grains far from the hole revealed that $\sim 50 \%$ deviate (by up to $6^{\circ}$ ) from one of the low-index ORs listed above, where the remainder do not have a low-index OR with the substrate (Figure 8).

The quite large deviation from a low-index OR for the normal grains can be explained by the fact that they are constrained by neighboring grains from all directions. Comparing the degree of deviation from low-index ORs, the abnormal grains at the edges of the holes have a narrower angular distribution compared to the normal-sized grains far from the hole. Furthermore, while many of the smaller grains were oriented far from one of the low-index ORs (more than $6^{\circ}$ ), all the abnormal grains adjacent to the holes were within $6^{\circ}$ of one of the low-index ORs.

To investigate the morphology and the orientation of the grains at the edges of the holes, site specific cross-section TEM specimens were prepared by FIB (Figure 9). Figure 9a presents a SEM micrograph of a typical hole in the Pt film, which was cross-sectioned, and Figure 9b shows a low magnification HAADF STEM micrograph of the hole and the faceted rims. The rim height decays discontinuously (by steps) with distance from the edge of the hole. In what follows the term 'secondary rim' is used to define the faceted film adjacent to the rim at the edge of the hole. These 'secondary rim' heights are smaller in height than the primary rim, but larger than the initial film thickness and appear to be faceted.

Figure 10 presents a TEM micrograph acquired after orienting the sapphire substrate in a $[1 \overline{1} 0 \overline{1}]$ zone axis, confirming the absence of a depression after the primary rim, which is in agreement with Klinger et al. [25] and Zucker et al. [26]. In addition, the steps forming the 'secondary rim' are located where grain boundaries intersect the free surface (Figure 11). The presence of a 'secondary rim' implies that continuous mass transport occurs across more than one grain during the retraction process. 
TEM micrographs and corresponding FFT's of the left rim in Figure 9 are presented in Figure 12 , to confirm the faceted nature of the Pt rim with the [111] normal direction and an OR with the sapphire substrate of $(\overline{1} \overline{1} 20)[1 \overline{1} 0 \overline{1}]_{\text {sapphire } \|}(1 \overline{1} \overline{1})[110]_{P t}$. Another OR found from a different abnormal Pt grain was $(\overline{1} \overline{1} 20)[1 \overline{1} 0 \overline{1}]_{\text {Sapphire } \|}(1 \overline{1} \overline{1})[211]_{P t}$ (Figure 13). These ORs are identical to two of the ORs which were found by EBSD. To better understand the mechanism which leads to formation of the primary rim, 'secondary rim' and the absence of the valley, AFM micrographs were acquired from 8 holes formed in the partially dewetted sample annealed for $70 \mathrm{~min}$, and an example is presented in Figure 14. The total volume of material removed from the hole was measured and found to be equal to the volume of material accumulated on the rim [39]. This implies that mass transport occurs from the hole to the rim, and that surface diffusion from the continuous film towards the rim does not occur or is extremely limited. In addition, AFM line-scans show that the heights of the rims adjacent to a specific hole are not identical, as explained by Kosinova et al. [40]. EBSD maps of the normal directions and TEM cross-sections confirmed that the upper surfaces of the faceted rims are $\{111\}$ for all abnormal grains along the hole edges. Therefore, surface anisotropy is not a sufficient explanation for the varying rim heights, and implies that other kinetic mechanisms are active, which depend on in-plane grain orientation or grain boundaries.

\section{Discussion}

\subsection{Microstructural Evolution}

The average grain size is a relative measure of the driving force for both grain growth and dewetting. Grain growth was observed during the dewetting process, where the initial average grain size of the as-deposited film was $\sim 30 \mathrm{~nm}$, and increased to $\sim 240 \mathrm{~nm}$ after 2 hours annealing. The stagnation diameter for an initial film thickness of 50nm was calculated to be $250 \mathrm{~nm}$ [19]. According to Frost et al. the driving force for normal grain growth decreases significantly when the average grain size reaches the stagnation size [19]. The presence of abnormal grains at the edges of the holes (which are 3-4 times larger than the average grain size) implies that a different driving force or other dominant diffusion mechanism exists at the edges of holes (Figure 4b). Assuming the same behavior at the edges of holes as in the continuous film, and assuming grain boundary diffusion to be the dominant mechanism for AGG, then AGG would be expected to occur within the continuous film as well as at the hole edges. The histogram which describes the average grain size for the sample annealed for 2 hours (Figure 5c) shows that while there are some grains in the range of $400 \mathrm{~nm}-600 \mathrm{~nm}$ in the continuous regions of the films, a bimodal distribution was not found, emphasizing that AGG in the continuous film does exist, but is minor compared to the degree of AGG localized to the edges of holes.

If surface diffusion is the dominant mechanism, material will accumulate at grains on the hole edges, according to diffusivity rates dictated by orientation, explaining rim formation [26]. However, this does not explain AGG of the grains at the edges of holes.

Frost et al. found that AGG will occur in a continuous film due to anisotropic surface energies, where grains with a particularly low surface energy will be those with the highest potential for AGG. In the following, the influence of anisotropic interface energy is considered to explain AGG and its subsequent influence on hole growth rate. The Ptsapphire system is anisotropic with regards to both the surface energy of Pt, and the interface energy between Pt and sapphire. If a Pt grain has a low energy OR with the substrate, then 
the system will want to increase the interface area of this grain with the substrate at the expense of its neighboring grains. This is a driving force for grain growth. There are always some Pt grains which in the as-deposited state do not have a low energy OR with the substrate. These grains will be consumed by the growing grains which have a low energy OR with the substrate. However, once holes have nucleated, these grains will be dewetted, while the driving force for dewetting of the Pt grains with a low energy OR with the substrate will be less.

Zucker et al. demonstrated that the formation of a faceted rim probably slows down edge retraction [26]. In the current system, the abnormal grains at the periphery of the holes also have a low-index OR with the substrate, indicating local minima of interface energy. These OR may also be close to the equilibrium configuration after dewetting has completed. Similar to the stagnation diameter for grain growth discussed by Frost et al. [19], the lowindex OR at the periphery of the hole implies a significant decrease in the driving force for dewetting. As such, dewetting will slow down when this phenomenon occurs, and probably stagnate until a local perturbation in the vicinity of the hole facilitates dewetting.

Figure 15 presents a schematic drawing presenting the morphological evolution of solid-state dewetting for a polycrystalline thin film with a significant degree of interface energy anisotropy. The dewetting process starts with (a) a continuous polycrystalline film where a few grains are close to a low-index OR (colored in light green; Figure 15a). During thermal annealing the holes form at relatively high energy triple lines, and this was experimentally confirmed to occur continuously during the dewetting process, in contrast to the model by Kosinova et al. which assumed a constant number of holes [40].

As the process continues the hole grows via surface diffusion resulting in mass accumulation on the rim. When the hole meets a grain with a low-index OR with the substrate, corresponding to a low interface energy, edge retraction is inhibited and the driving force for that grain to grow is significantly larger than for the neighboring grains. Simultaneously, the hole continues to grow in directions where the grains have a higher interface energy with the substrate. In those directions when a retracting hole eventually meets with a Pt grain with a low-index OR with the substrate, the rim height will be significantly higher than where the first stagnation event occurred (Figure 15f).

A significant degree of deviation from a low-index OR, or a high angle grain boundary can serve as a fast diffusion path and may affect the diffusion rate resulting in 'secondary' rims where the first grain at the edge serves as a diffusion path for adjacent grains. The existence of the rims (primary and secondary), which are much thicker than the initial film thickness, will also retard the dewetting rate [26].

\section{$5 \quad$ Summary and Conclusions}

Solid-state dewetting of Pt thin films on sapphire substrates was used to characterize the morphological evolution and the overall kinetic behavior. Extensive EBSD investigations of the second stage of dewetting were conducted. It was experimentally demonstrated that $\mathrm{Pt}$ grains with a low-index OR with the sapphire substrate play an important role in the dewetting kinetics, rim heights and formation of abnormal grains adjacent to holes.

In partially dewetted samples where abnormal grains were observed adjacent to holes, the grains had a low-index OR with the substrate and faceted rims parallel to \{111\}. In addition, the rim heights along the periphery of individual holes were not equal, suggesting that surface 
diffusion is not the only factor which affects mass accumulation on the rim, and that the OR with the sapphire substrate strongly influences the rim height. Grains with a low-index OR with the substrate have a significantly larger driving force for grain growth, resulting in AGG in the film, which stagnates hole growth, resulting in holes decorated with abnormal grains.

\section{Acknowledgments}

The authors thank N. Bozzolo for assistance with the EBSD software. C. Handwerker, M. Kammer, J. Blendell, and E. Rabkin are acknowledged for discussions. This research was partially supported by the Russel Berrie Institute for Nanotechnology at the Technion.

\section{References}

1. Aouassa M, Berbezier I, Favre L, Ronda A, Bollani M, Sordan R, Dellobe A, Sudraud P. Applied Physics Letters 2012;101;013117.

2. Danielson DT, Sparacin DK, Michel J, Kimerling LC. Journal of Applied Physics 2006;100:10.

3. Randolph SJ, Fowlkes JD, Melechko AV, Klein KL, H. M. Meyer I, Simpson ML, Rack PD. Nanotechnology 2007;18:465304.

4. Mikhelashvili V, Shneider Y, Meyler B, Atiya G, Yofis S, Cohen-Hyams T, Kaplan WD, Lisiansky M, Roizin Y, Salzman J, Eisenstein G. Journal of Applied Physics 2012;112:024319.

5. Mikhelashvili V, Meyler B, Shneider Y, Yofis S, Salzman J, Atiya G, Cohen-Hyams T, Ankonina G, Kaplan WD, Lisiansky M, Roizin Y, Eisenstein G. Journal of Applied Physics 2013;113:074503.

6. Kwon J-Y, Yoon T-S, Kim K-B, Min S-H. Journal of Applied Physics 2003;93:3270.

7. $\quad$ Müller CM, Spolenak R. Journal of Applied Physics 2013;113:094301.

8. $\quad$ Sebastian S, Kirendall C, Chang JB, Berggren KK. Nanotechnology 2010;21:505301.

9. Meltzman H, Chatain D, Avizemer D, Besmann TM, Kaplan WD. Acta Materialia 2011;59:3473.

10. Kaplan WD, Chatain D, Wynblatt P, Carter WC. Journal of Materials Science 2013;48:5681.

11. Ni N, Kaufmann Y, Kaplan WD, Saiz E. Acta Materialia 2014;64:282.

12. Mullins WW. Journal of Applied Physics 1957;28:333.

13. Mullins WW. Journal of Applied Physics 1959;30:77.

14. Srolovitz DJ, Safran SA. Journal of Applied Physics 1986;60:247.

15 Schmirgeld-Mignot L, Molinas-Mata PJA, Poissonnet S, Martin G. Philosophical Magazine Letters 2000;80:33.

16. Shaffir E, Riess I, Kaplan WD. Acta Materialia 2009;57:248.

17. Atkinson HV. Acta Metallurgica 1988;36:469.

18. Mullins WW. Acta Metallurgica 1958;6:414.

19. Frost HJ, Thompson CV, Walton DT. Acta Metall. Mater. 1990;38:1455.

20. Frost HJ, Thompson CV, Walton DT. Acta Metall. Mater. 1992;40:779.

21. Müller CM, Spolenak R. Acta Materialia 2010;58:6035.

22. Brandon RH, Bradshaw FJ. Technical report. Farnborough: Royal Aircraft Establishment; 1966.

23. Jiran E, Thompson CV. Journal of Electronic Materials 1990;19:1153.

24 Srolovitz DJ, Safran SA. Journal of Applied Physics 1986;60:247.

25. Klinger L, Amram D, Rabkin E. Scripta Materialia 2011;64:962.

26. Zucker RV, Kim GH, Craig Carter W, Thompson CV. Comptes Rendus Physique 2013;14:564. 
27. Beszeda I, Beke DL. Applied Physics A 1997;64:583.

28. Amram D, Klinger L, Rabkin E. Acta Materialia 2012;60:3047.

29. Jiran E, Thompson CV. Thin Solid Films 1992;208:23.

30. Funk M, Meister S, Grain and particle analysis with line intersection method, Matlab code, Copyright (c), 2012.

31. Rasband W, Image J 1.42q, National Institute of Health, USA, http://rsb.info.nih.gov/ij.

32. Scanning Probe Image Processor (SPIP) software, version 6.2.8, Image Metrology.

33. Thangadurai P, Lumelsky Y, Silverstein MS, Kaplan WD., Materials Characterization 2008;59:1623.

34. Baram M, Kaplan WD. Journal of Microscopy, 2008;232:395.

35. Chaudhari P. Journal of Applied Physics 1974;45:4339.

36. Hahn TA, Kirby RK. AIP Conference Proceedings, No. 3, 1972.

37. Engberg CJ, Zehms EH, Commission USAE, Division NAAAI. Thermal Expansion of $\mathrm{Al}_{2} \mathrm{O}_{3}, \mathrm{BeO}, \mathrm{MgO}, \mathrm{B} 4 \mathrm{C}, \mathrm{SiC}$, and TiC Above $1000^{\circ} \mathrm{C}$ : Atomics International, 1958.

38. Curiotto S, Chien H, Meltzman H, Labat S, Wynblatt P, Rohrer G, Kaplan WD, Chatain D. Journal of Materials Science 2013;48:3013.

39. Kovalenko O, Greer JR, Rabkin E, Acta Materialia, 2013;61:3148.

40. Kosinova A, Klinger L, Kovalenko O, Rabkin E. Scripta Materialia 2014;82:33. 


\section{Figure Captions}

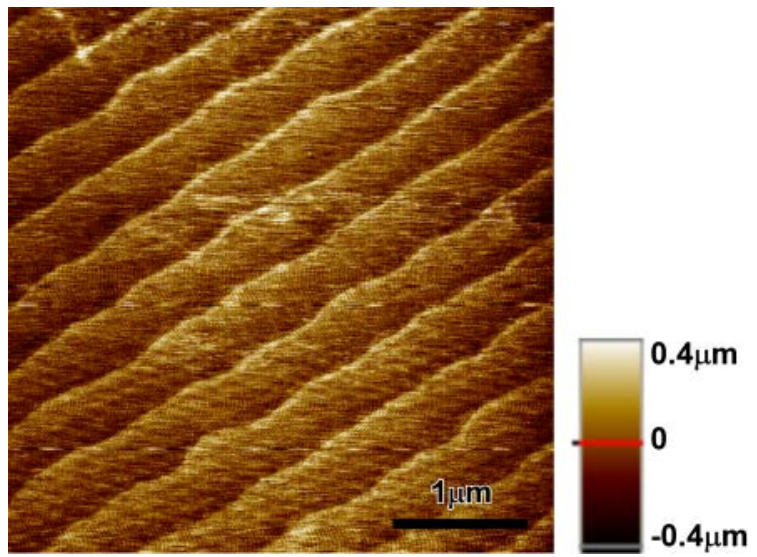

Figure 1: AFM micrograph of an A-plane sapphire substrate annealed at $1100^{\circ} \mathrm{C}$ for 2 hours in $\mathrm{Ar}+\mathrm{H}_{2}$, before Pt deposition. The surface consists of anisotropic terraces and steps. The width of the terraces is $\sim 400 \mathrm{~nm}$, and the step heights are $\sim 0.3 \mathrm{~nm}$.

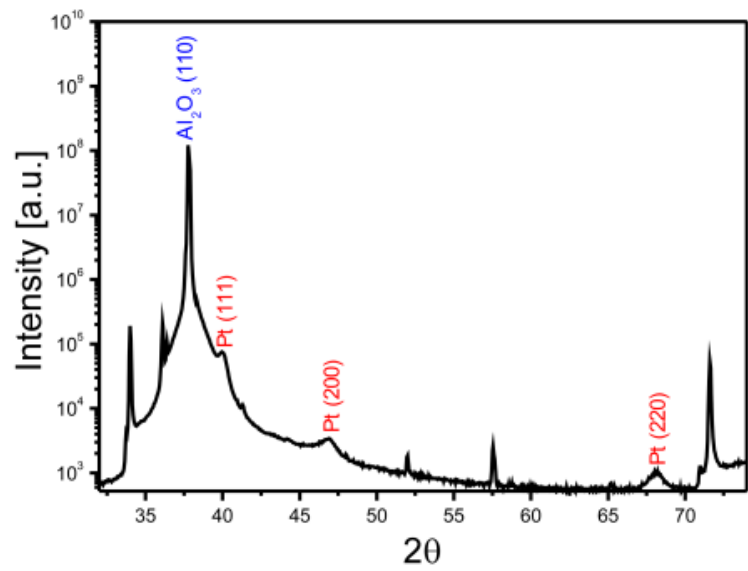

Figure 2: XRD pattern obtained from the as-deposited Pt film on A-plane sapphire. The unlabeled narrow peaks correspond to double diffraction and $\mathrm{K}_{\beta}$.

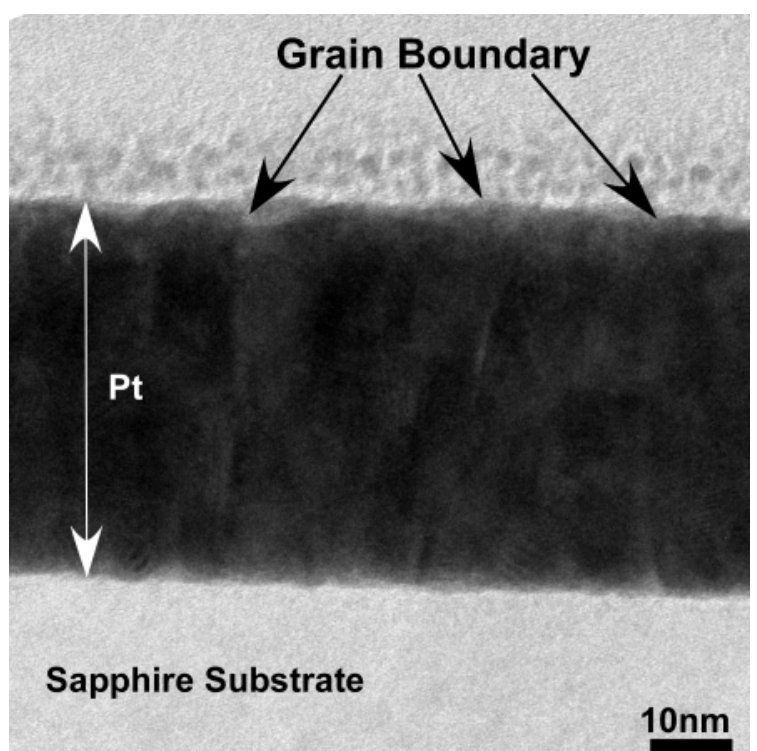


Figure 3: Bright field diffraction contrast TEM micrograph of a cross-section of the asdeposited Pt film on A-plane sapphire, confirming that the as-deposited Pt thickness was $\sim 50 \mathrm{~nm}$. The Pt grains are columnar, and their width is $\sim 20-30 \mathrm{~nm}$.
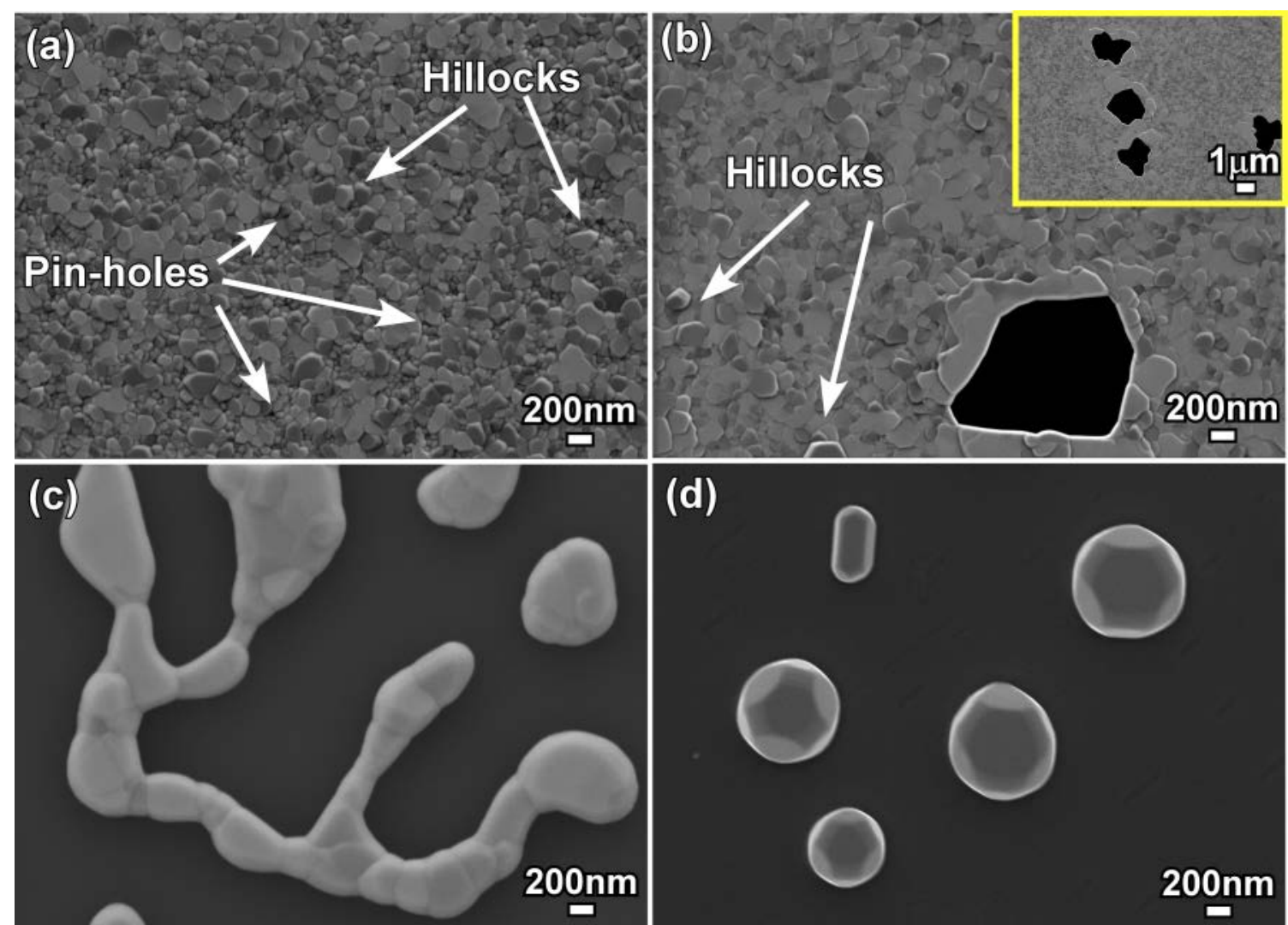

Figure 4: Secondary electron HRSEM micrographs of a $50 \mathrm{~nm}$ Pt film annealed at $800^{\circ} \mathrm{C}$ for (a) $1 \mathrm{~min}$, showing grain growth, the formation of pin-holes, and hillocks; (b) 2hr, showing hole growth with faceted abnormal grain growth at the edges of holes; (c) 4hr showing the formation of "fingers" or the Rayleigh instability; and (d) 48hr showing Pt particles close to equilibrium.
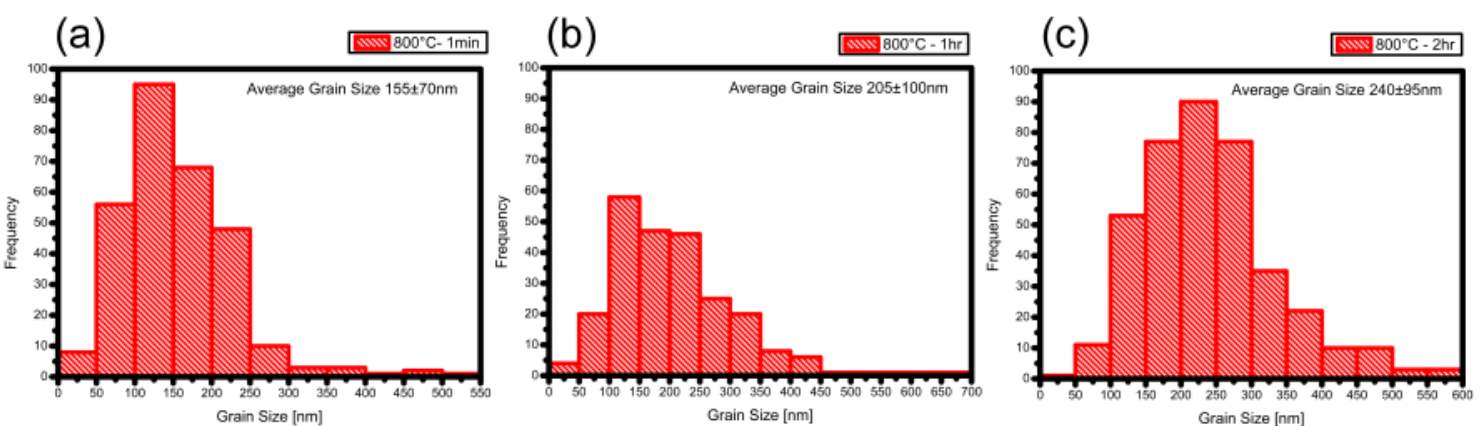

Figure 5: Grain size analysis of the partially dewetted Pt film (a) after 1 minute; (b) after 1 hour; and (c) after 2 hours at $800^{\circ} \mathrm{C}$ in $\mathrm{Ar}+\mathrm{H}_{2}$, indicating grain growth during dewetting. Note that abnormal grains were not considered in the analysis. 


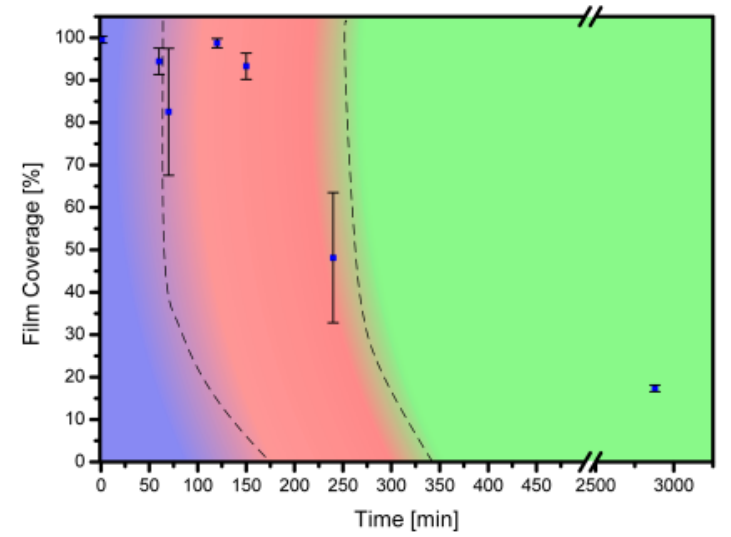

Figure 6: Film coverage as a function of annealing time at $800^{\circ} \mathrm{C}$. The first stage of hole nucleation is indicated by blue, the second stage of hole growth is indicated by red, and the third stage of particle formation is indicated by green.
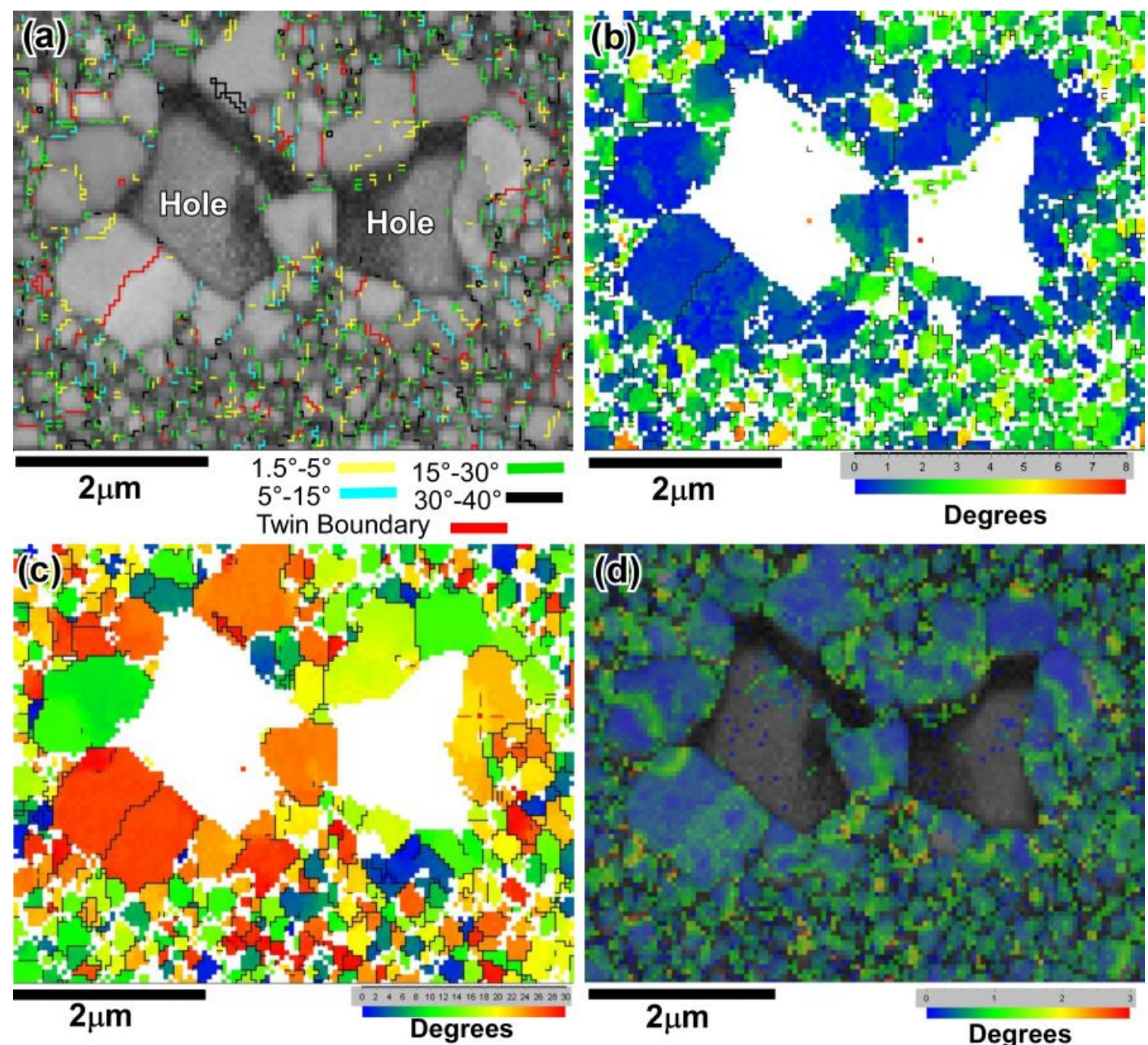

Figure 7: (a) Secondary electron SEM micrograph with superimposed EBSD data for a partially dewetted $\mathrm{Pt}$ film annealed at $800^{\circ} \mathrm{C}$ for 2 hours in $\mathrm{Ar}+\mathrm{H}_{2}$, indicating the misorientation angle for each Pt grain boundary. (b) EBSD map showing the degree of deviation of Pt grains from a [111] normal to the substrate surface. The abnormal grains located at the edges of holes, colored in blue, correspond to $0^{\circ}$ deviation from the [111] normal direction. (c) Texture map of [110] parallel to the X direction (in-plane). Color coding 
corresponds to a misorientation from [110] parallel to the X-direction. (d) Average local misorientation map. The misorientation in some of the larger grains may be due to strain.

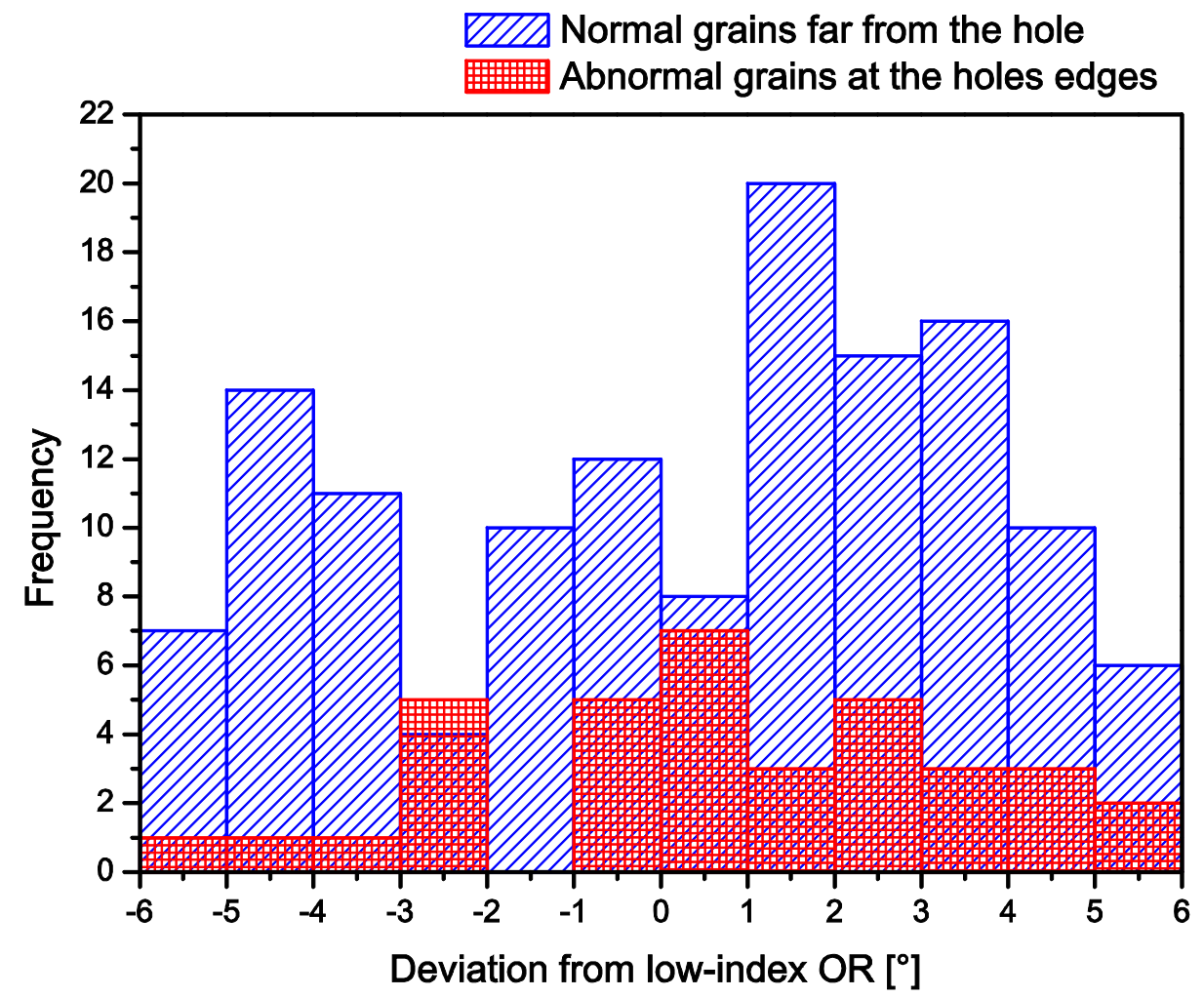

Figure 8: Histogram analysis of the angular deviation from an exact low-index orientation relationship of the abnormal grains adjacent to holes, compared to the general population of grains far from the holes. Note that for the general population of grains far from the holes, grains with a deviation larger than $6^{\circ}$ are not plotted.
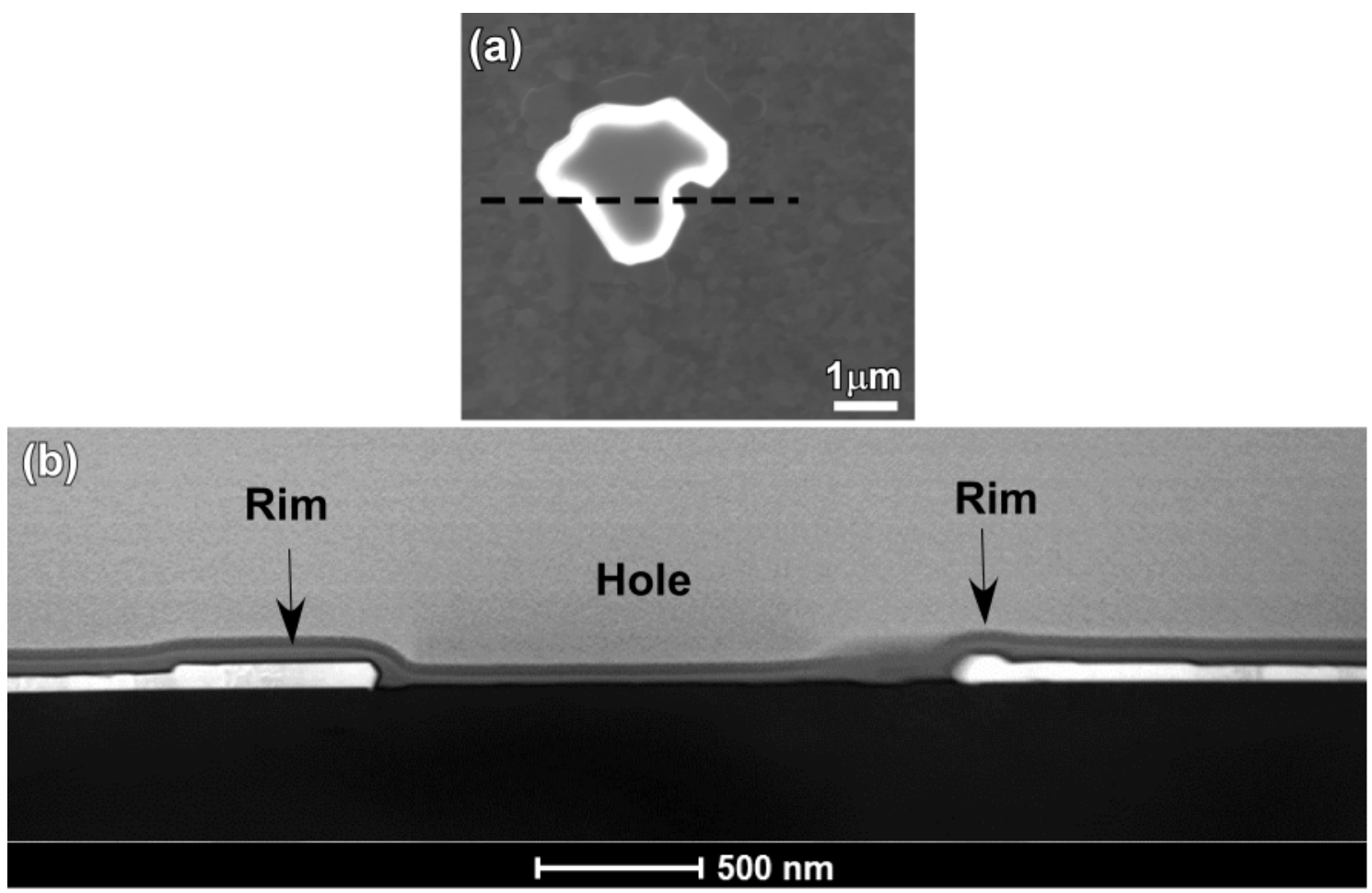
Figure 9: (a) HRSEM micrograph of a hole formed in the Pt film after annealing at $800^{\circ} \mathrm{C}$ for 2 hours in $\mathrm{Ar}+\mathrm{H}_{2}$. (b) Low magnification HAADF STEM micrograph of the cross-sectioned hole (prepared along the dashed line shown in (a)) and the rims at the retracting edge.
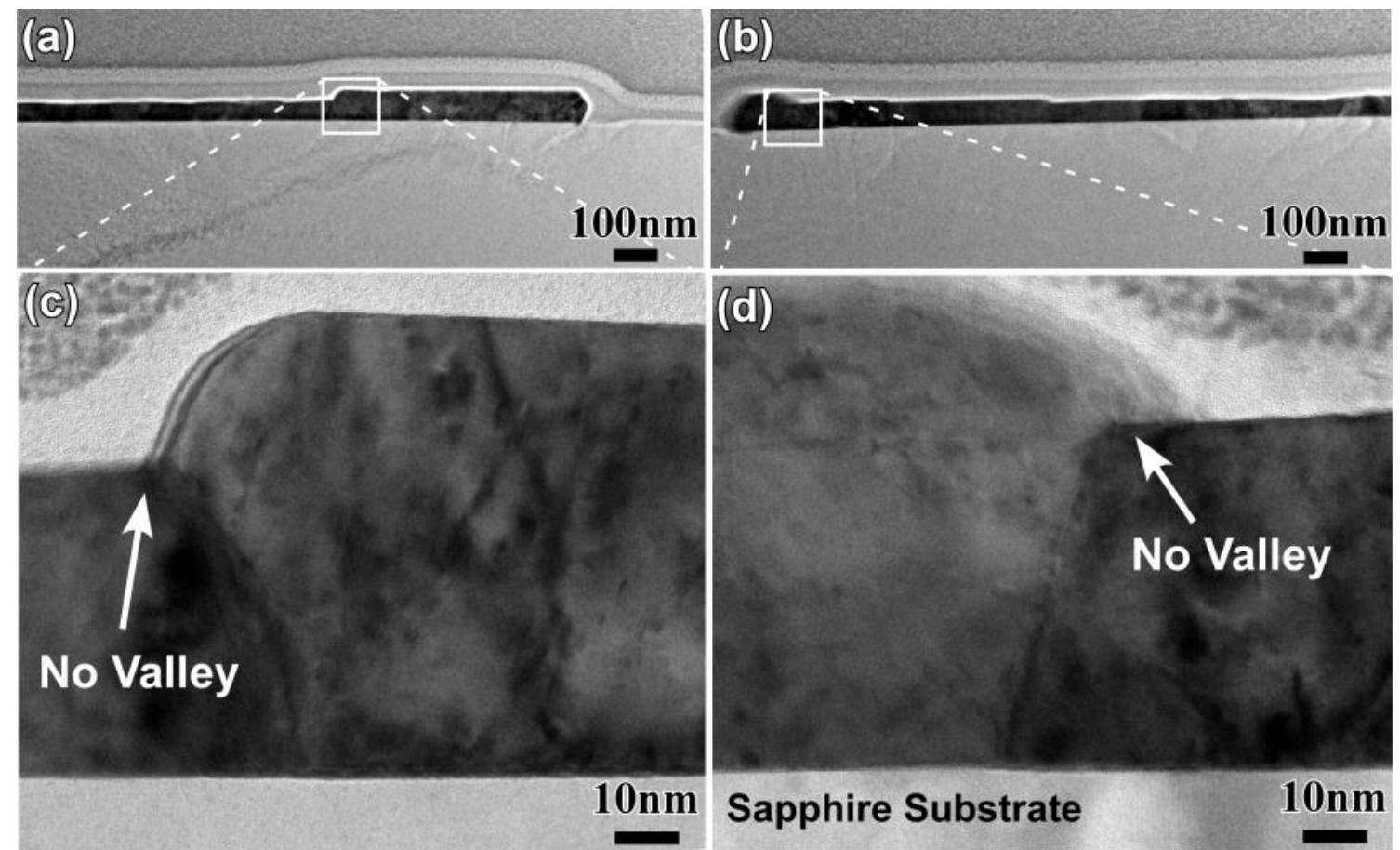

Figure 10: (a) and (b) Bright field TEM micrographs of the rims shown in Figure 9 acquired after orienting the sapphire substrate in a $[1 \overline{1} 0 \overline{1}]$ zone axis, and (c) and (d) higher magnification micrographs of the rims showing the absence of a valley between the rim and the film.

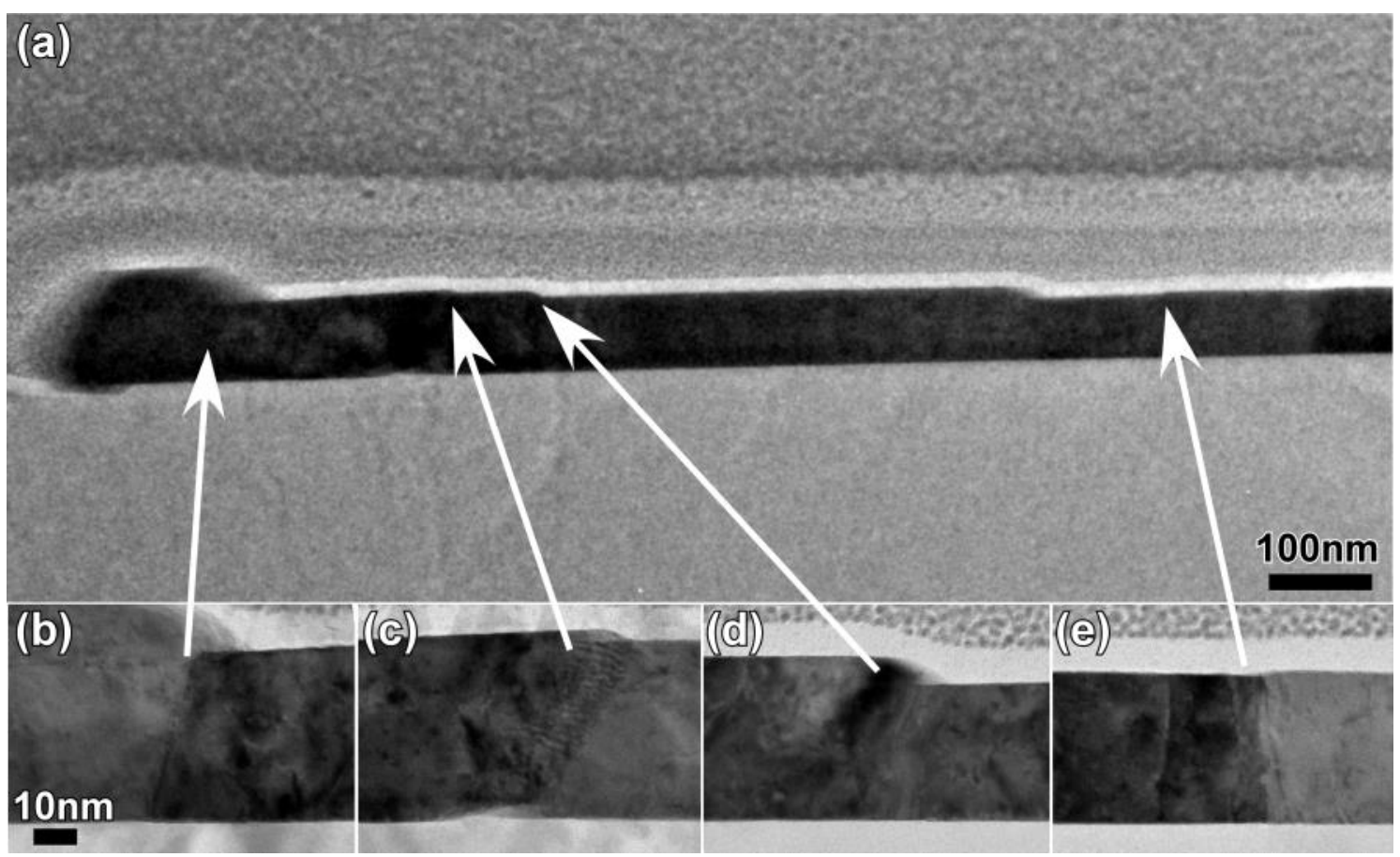

Figure 11: Steps on the Pt film surface. The steps form at GBs which intersect the surface, resulting in 'secondary' rims. 

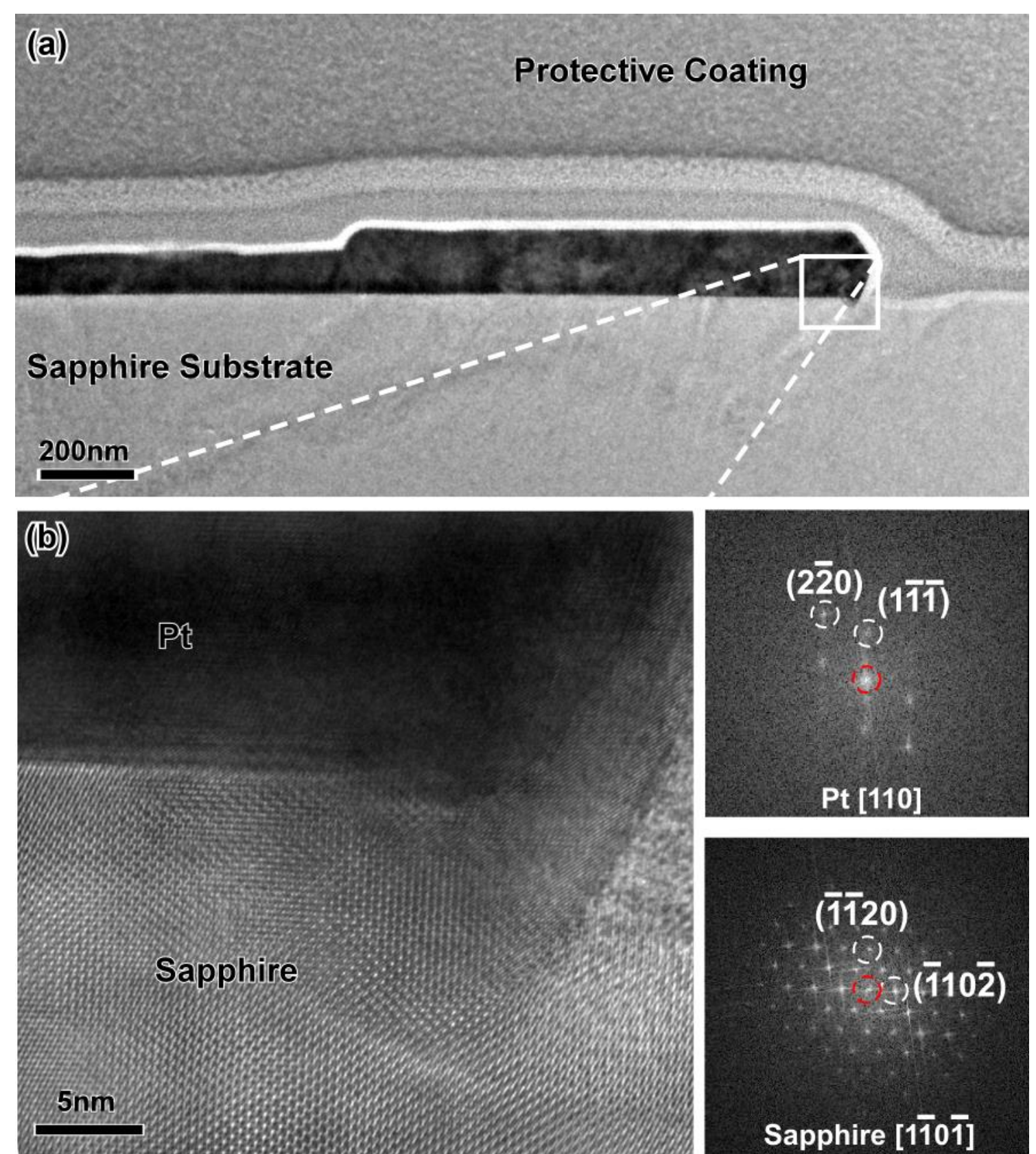

Figure 12: (a) TEM micrograph of the left side of the cross-sectioned hole shown in Figure 9, after orienting the sapphire in a $[1 \overline{1} 0 \overline{1}]$ zone axis, showing the faceted rim and the steps on the Pt surface. (b) Higher magnification micrograph from the region indicated in (a). Fourier transforms serve to indicate the Pt and sapphire orientations.

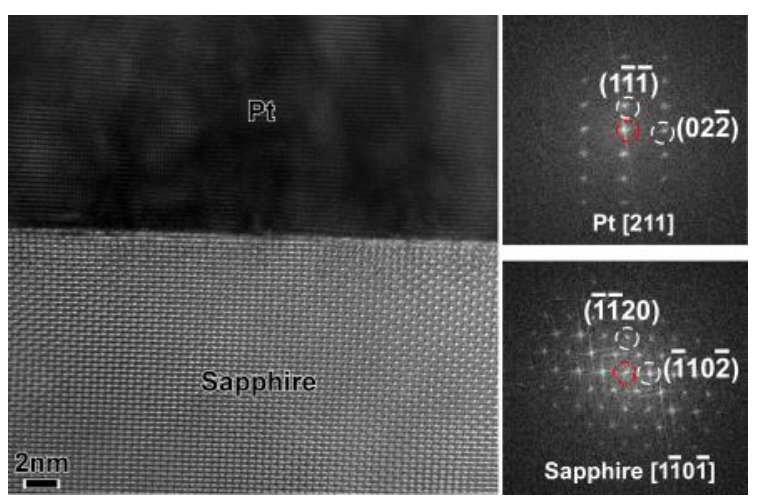


Figure 13: Cross-section HRTEM micrograph of the left side of the hole shown in Figure 9, after orienting the sapphire substrate in a $[1 \overline{1} 0 \overline{1}]$ zone axis, and corresponding FFT's from the sapphire substrate and Pt grain.

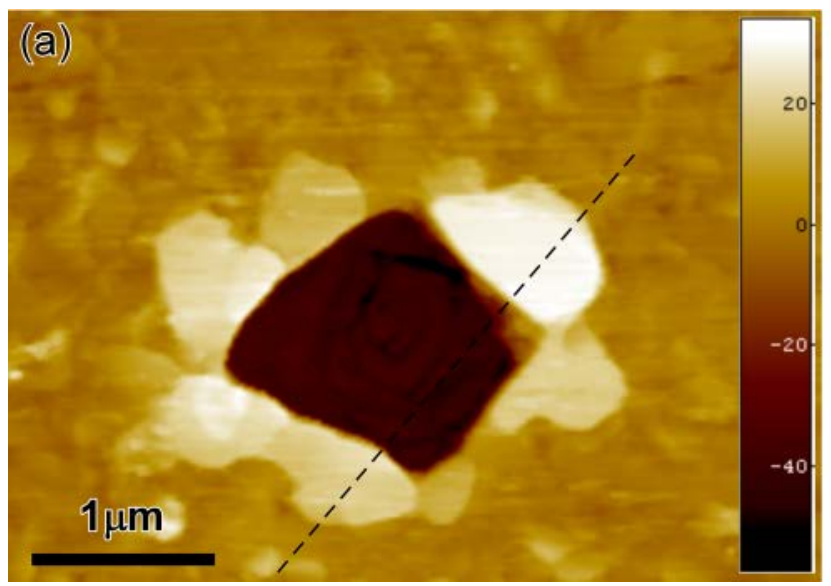

(b)

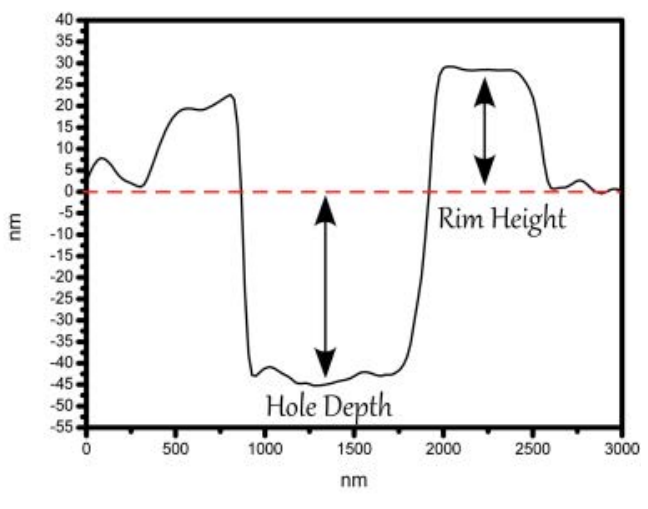

Figure 14: (a) AFM micrograph of a hole formed in the Pt film annealed at $800^{\circ} \mathrm{C}$ for $70 \mathrm{~min}$ in $\mathrm{Ar}+\mathrm{H}_{2}$ and (b) corresponding line topography profile acquired along the black dashed line in (a), showing the relative film height and hole depth.

(a)

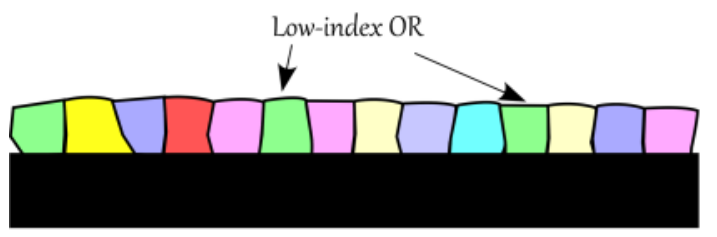

(b)

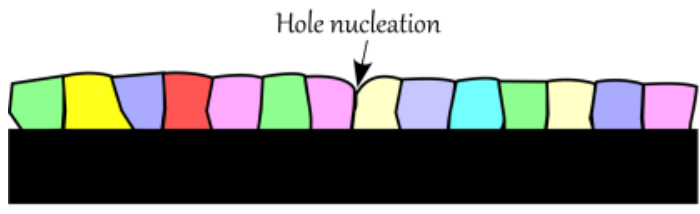

(c)

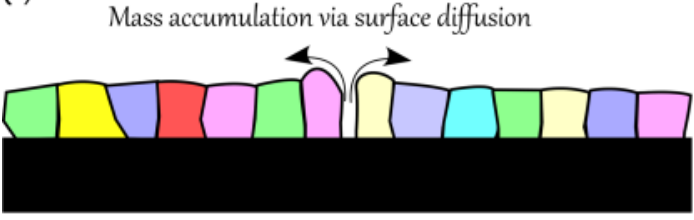

(d) Mass accumulation via surface diffusion

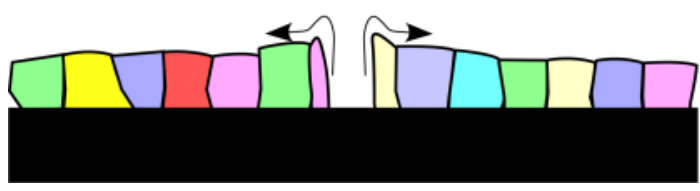

(e)

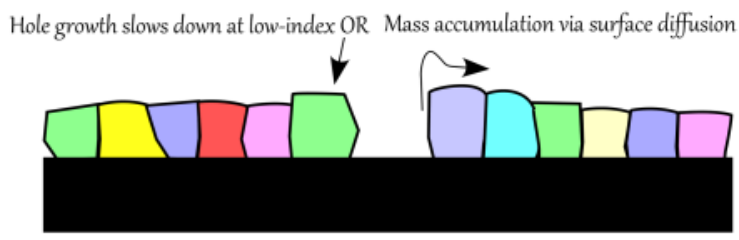

$(f)$

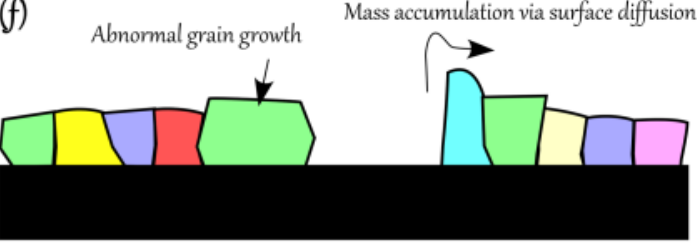

(g)

Mass accumulation via surface diffusion

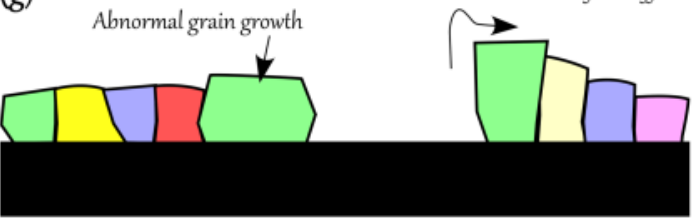

(h)

Abnormal grain growth

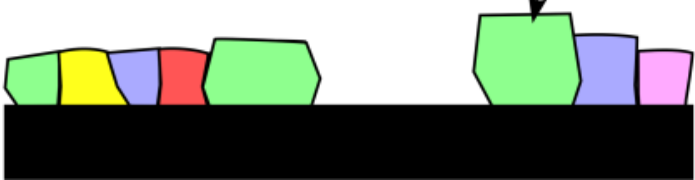

Figure 15: Schematic drawing of the dewetting process presenting the morphological evolution of solid-state dewetting for a polycrystalline thin film with a significant degree of interface energy anisotropy. The dewetting process starts with (a) a continuous polycrystalline film where a few grains are close to a low-index OR (colored in light green) with the substrate. (b) During thermal annealing the holes form at relatively high energy triple lines via grain boundary grooving or voids at the interface. $(c+d)$ As the process continues the hole grows via surface diffusion resulting in mass accumulation on the rim. (e) When the hole meets a grain having a low-index OR with the substrate, corresponding to a 
low interface energy, edge retraction is inhibited due to the reduced driving force for dewetting. (f) The grain where retraction was inhibited continuous to grow at the expense of neighboring grains which do not have a low-index OR with the substrate, resulting in abnormal grain growth, and the hole continues to grow in directions where grains along the hole edge have a higher interface energy with the substrate. (g) In those directions when the retracting hole eventually meets a Pt grain with a low-index OR with the substrate, the rim height will be significantly higher than where the first stagnation event occurred. 